\title{
THE POSSIBILITY OF APPLYING ACOUSTIC EMISSION METHOD FOR MONITORING LATHING PROCESS
}

\author{
Krzysztof Dudzik \\ Gdynia Maritime University, Faculty of Marine Engineering \\ Morska Street 81-87, 81-225 Gdynia, Poland \\ tel.: +48585586 549, fax: +48585586 399 \\ e-mail:k.dudzik@wm.umg.edu.pl
}

\begin{abstract}
Nowadays acoustic emission (AE) method is used in many fields of science, including in the diagnosis and monitoring of machining processes such as turning, grinding, milling, etc. Monitoring of turning process allows ensuring stable conditions of treatment. Stable conditions of turning process have a great impact on the quality of the surface. This is especially important during finishing treatment.

The research was carried out on a universal ZMM-SLIVEN CU500MRD lathe centre-using tool with removable insert SANDVIK Coromant WNMG 080408 - WMX Wiper. Lathing process was performed on the shaft of $74 \mathrm{~mm}$ in diameter made of $S 235$ steel.

The research was carried out at constant cutting speed $v=230 \mathrm{~m} / \mathrm{min}$. Changed parameters were feed $f=0.1 ; 0.2$; $0.4 \mathrm{~mm} / \mathrm{rev}$ and cutting depth ap $=0.5 ; 0.75 ; 1 \mathrm{~mm}$. In the research was used a set of acoustic emission Vallen System. The kit includes: 4 channel signal recorder AMSY 6, two measurement modules ASIP-2/S, preamplifier with a frequency range $20 \mathrm{kHz}-1 \mathrm{MHz}$ and the strengthening of $34 \mathrm{~dB}$ and AE signal measurement sensor type VS 150M, with a frequency range $100-450 \mathrm{kHz}$. During the study, the acoustic emission (AE) generated during the lathing process were recorded parameters e.g. amplitude, number of events - hits, the effective value of the signal (RMS).

The test results indicate, that the higher instability of the process was during turning with parameters: ap $=0.75 \mathrm{~mm}$ and $f=0.1 \mathrm{~mm} / \mathrm{rev}$. The study can be the basis for the use of acoustic emission method for monitoring lathing process to ensure stable conditions of that process and the same to obtain a high quality surface.
\end{abstract}

Keywords: Acoustic Emission (AE), diagnostic, finishing treatment, lathing, cutting parameters

\section{Introduction}

The most common method of the surface layer forming is lathing. Conventional machining accuracy is usually considered as a function of the characteristics of all the components of machine tool, fixture, object, tool. There is accuracy performance, and the accuracy of static and dynamic determining and cutting parameters, which are associated with strength, temperature, and wear of the cutting edge $[7,8]$.

To obtain a high surface quality should be optimized determination of cutting parameters. Manufacturers of tools give ranges of recommended parameters, but in order to achieve the best possible surface area is necessary to define the exact parameters. One of the criteria for the selection of turning performance is to reduce the tool vibration, which results in surface quality. This is particularly important for finishing treatment. On the other hand, there is requirement of high machining efficiency as possible in order to reduce production costs.

One of the methods for monitoring and optimization of the machining process for selection of cutting parameters is the acoustic emission (AE) method. Acoustic emission is considered as nondestructive methods. According to the definition acoustic emission (AE) is an evanescent elastic wave, which is the result of rapid release of the energy stored in the material by propagating a microdamage (increase in micro-cracks, the movement of groups of dislocations) in the material or by a process (friction, leakage, etc.) [9-11]. The typical frequency range of the acoustic emission is normally determined in $20 \mathrm{kHz}-2 \mathrm{MHz}[9,12]$. 
Acoustic Emission (AE) is a passive non-destructive method. Its main advantages are [2]:

- high sensitivity of AE,

- the possibility of conducting continuous research,

- the possibility to locate the source of the AE signals generated by the damage, leaks, etc.

- the possibility of carrying out research without having to shut down equipment out of service.

The stimulus causing the release of energy and the formation of elastic waves can be: load operation, environment, temperature change, and the processes which are accompanied by acoustic emission changes both at the micro and the macro scale, such as: cracks, friction, plastic deformation, corrosion, leaks, structural and phase changes, chemical reactions, delamination, cracking of the fibres and matrix in composites, etc. [1,2].

The acoustic waves propagate in all directions from the source; can thus be recorded by one or more sensors mounted on an object or component. During the propagation, waves are suppressing the AE, which limits the distance over which they may be detectable. This distance is dependent on many factors, including mainly on properties of the material, the geometry of the object and the level of interference from background noise [3-5]. An example of AE signal is shown in Fig. 1.

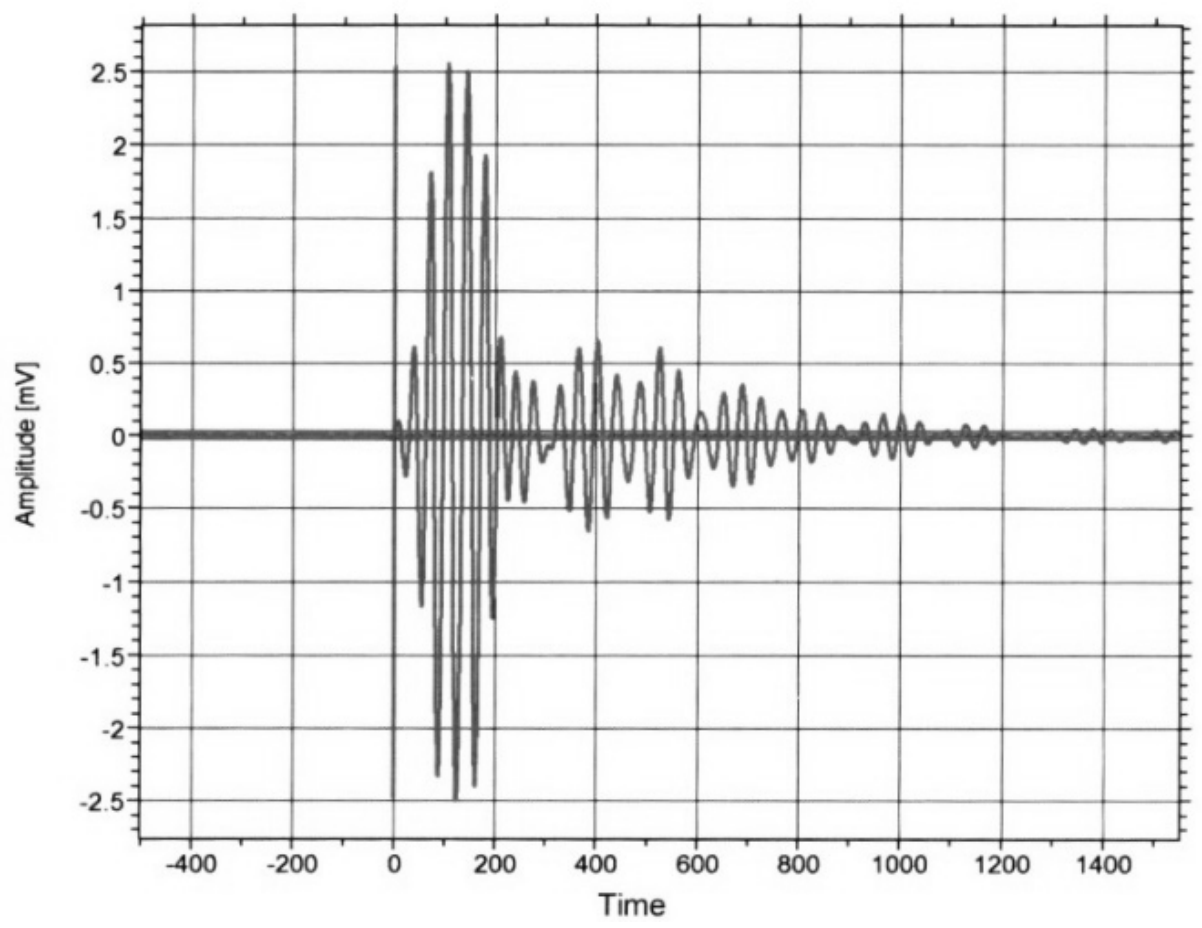

Fig. 1. An example of typical Acoustic Emission burst signal [12]

AE signal can be characterized by parameters such as amplitude, energy, rise time, duration, number of exceedances of the threshold of discrimination - hits, RMS of the signal, etc.

Processes occurring in the material during machining generate elastic waves that can be registered by appropriate measuring system. The basic sources of acoustic emission in the machining process are [6]:

- plastic deformation of the workpiece in the abrasion zone,

- plastic deformation and friction between the rake face of the tool and the chip,

- the friction between the tool principal flank surface and the workpiece,

- forming, tangling and breaking of the chip,

- shock wave, which arises when the tool enters the workpiece,

- sudden breakage of the chip when the tool exits the workpiece.

Potential sources of acoustic emission during turning are shown in Fig. 2. 


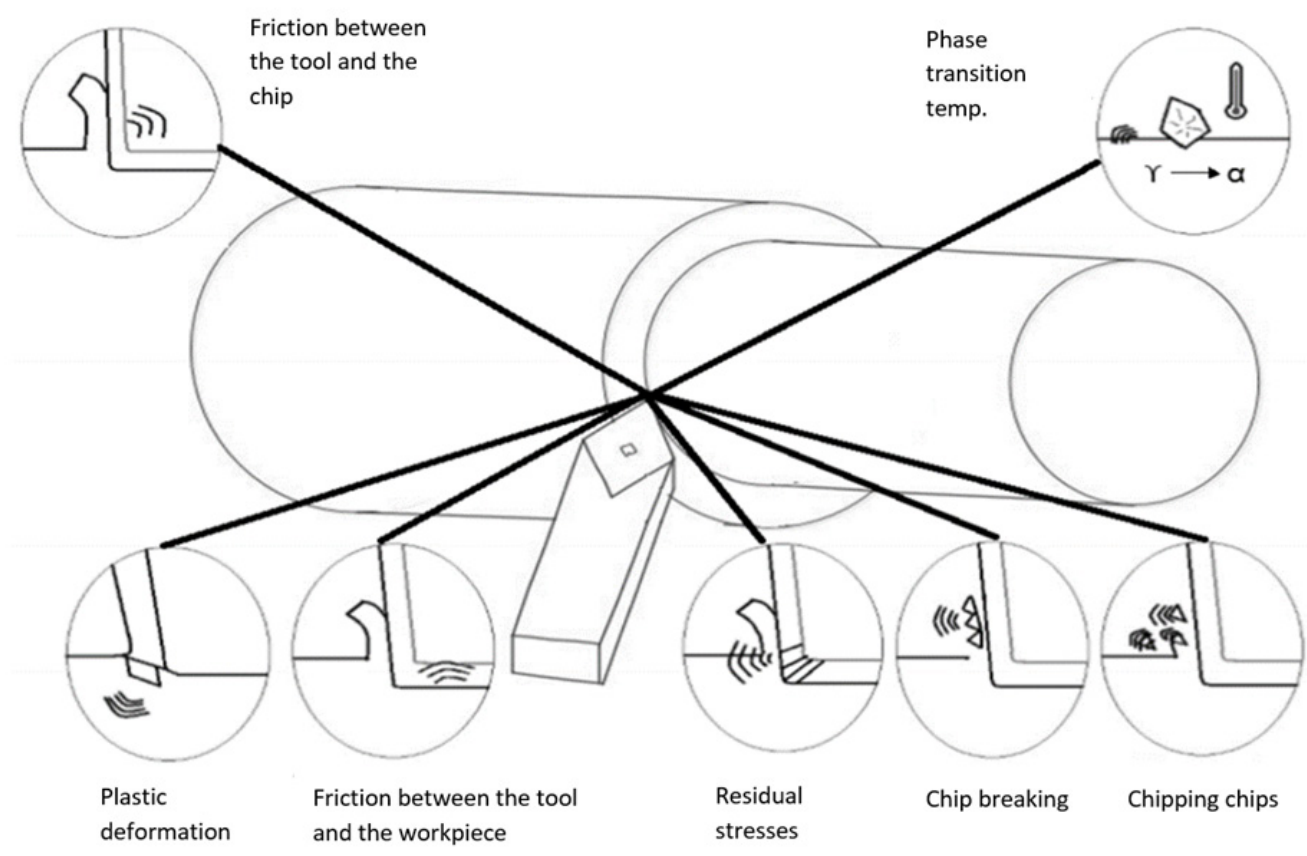

Fig. 2. Potential sources of acoustic emission during turning [6]

The article presents the possibility of using acoustic emission method for monitoring lathing process.

\section{Research methodology}

The process of turning shaft ( $\phi 74 \mathrm{~mm})$ made of $\mathrm{S} 235$ steel was carried out on a universal ZMMSLIVEN CU500MRD lathe centre. The lathing process was conducted by a cutting tool with SANDVIK Coromant WNMG 080408 - WMX Wiper removable insert. Dedicated holder for chosen insert was SANDVIK Coromant DWLNR 2525M 08. The view of tool used in research is shown in Fig. 3.

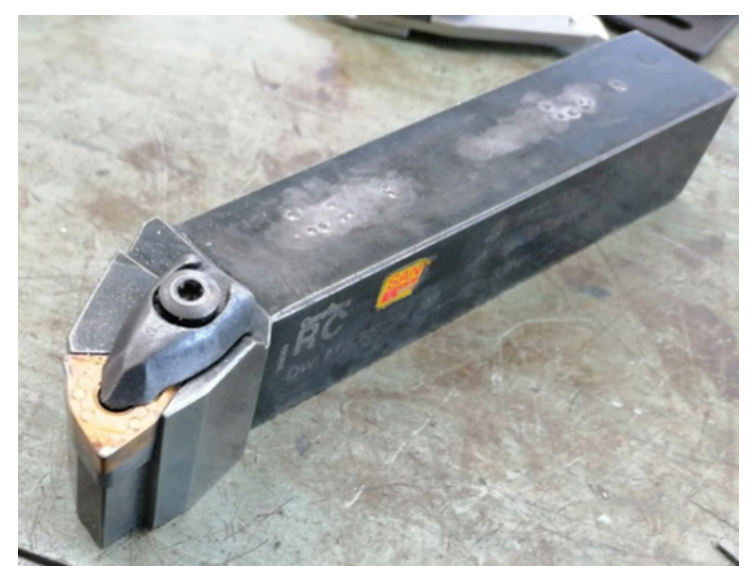

Fig. 3. View of tool used in research

The view of equipment used in research is presented in Fig. 4.

Cutting parameters were selected on the basis on the data of cutting tool manufacturer. The research was carried out at constant cutting speed $\mathrm{Vc}=230 \mathrm{~m} / \mathrm{min}$. Changed parameters were feed $\mathrm{f}=0.1 ; 0.2 ; 0.4 \mathrm{~mm} / \mathrm{rev}$ and cutting depth $\mathrm{ap}=0.5 ; 0.75 ; 1 \mathrm{~mm}$. For monitoring this process acoustic emission method was used. 


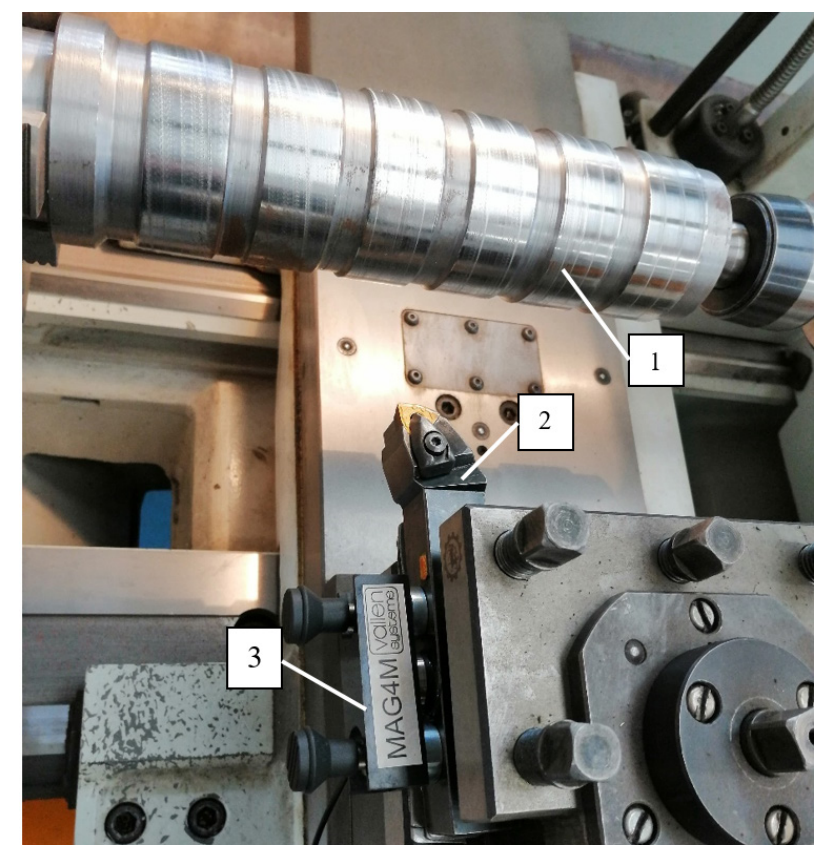

Fig. 4. The view of equipment used in research: 1-shaft, 2 -tool, 3 - AE sensor with magnetic holder

Research of acoustic emission (AE) accompanying the lathing process was performed using a kit consisting of 4-channel signal recorder type AMSY 6 and two measuring modules ASIP-2/S from Vallen System. The kit includes pre-amplifier with a frequency range of $20 \mathrm{kHz}-1 \mathrm{MHz}$ and the strengthening of $34 \mathrm{~dB}$ and a sensor signal measurement AE, VS $150 \mathrm{M}$, with a frequency range of $100-450 \mathrm{kHz}$. The system includes a data-recording module $-8 \mathrm{MB}$ per channel and software for recording and analysing $\mathrm{AE}$ data. The sensor is mounted on the surface of the tool by means of a magnetic holder MAG4M - dedicated to the sensor used. Between the sensor and the surface, the coupling fluid was used.

\section{Research results}

During the study, the acoustic emission (AE) generated by the lathing process carried out on a test, recorded a number of parameters which were analysed. These parameters were e.g. amplitude, number of events - hits, energy, RMS of the signal. The analysis of those parameters was performed using Vallen Visual AE software.

Figure 5 shows exemplary signal amplitude as a function of time recorded during research.

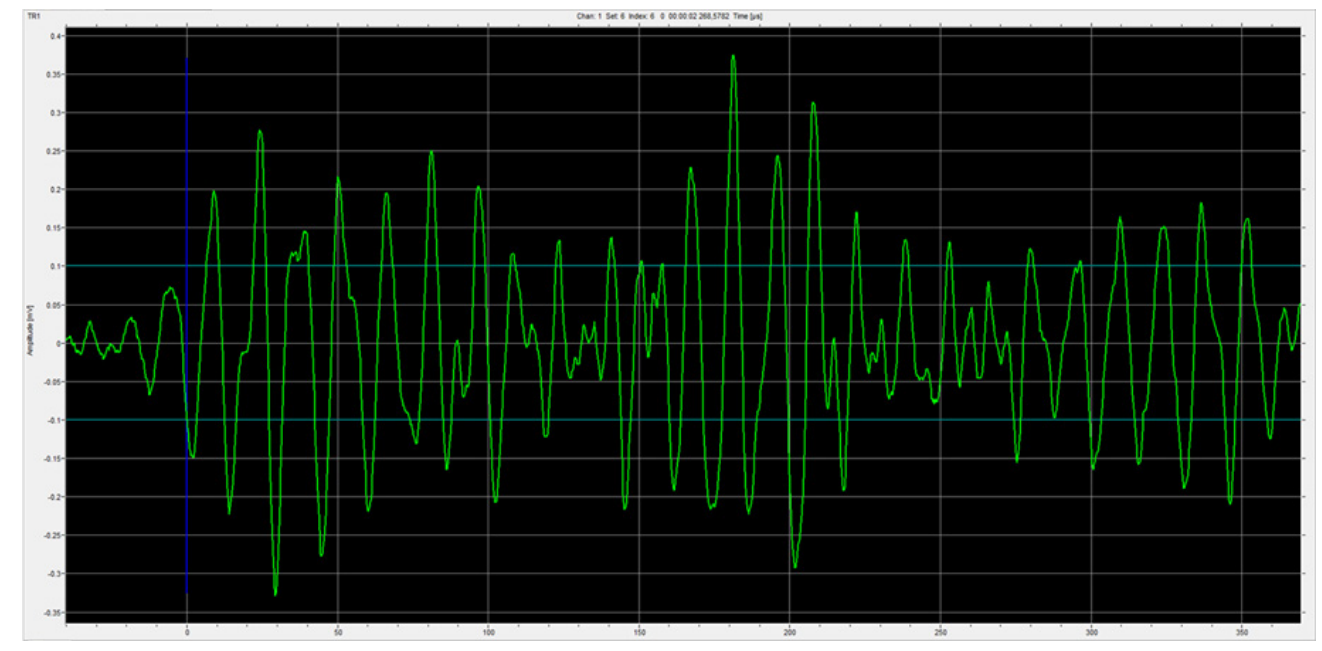

Fig. 5. An example of the AE sampled signal recorded during turning 
Additionally, analysis of recorded signals after FFT (Fast Fourier Transform) allows defining nature of the phenomenon on the basis of their frequency. Relatively low frequency confirms stable conditions of the turning process. Range of frequency was similar for all measurements.

Figure 6 shows exemplary signal amplitude as a function of the frequency recorded during research.

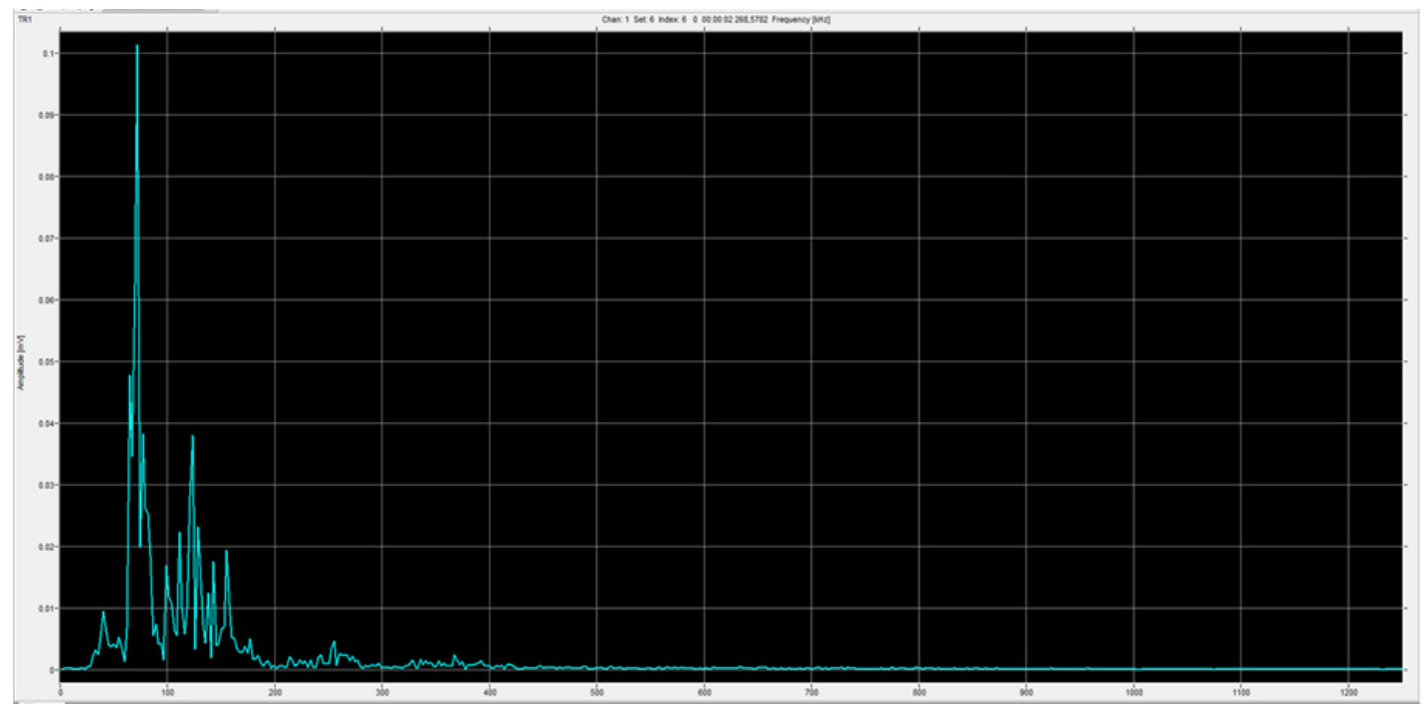

Fig. 6. An example of the AE signal after FFT analysis recorded during turning

The research results were shown in Tab. 1. Those are average values of chosen parameters: amplitude and RMS of the signals and their standard deviation.

Tab. 1. Average values of chosen parameters and their standard deviation

\begin{tabular}{|c|c|c|c|c|c|}
\hline \multirow{2}{*}{$\begin{array}{c}\mathrm{f} \\
{[\mathrm{mm} / \mathrm{rev}]}\end{array}$} & \multirow{2}{*}{$\begin{array}{c}|c| \\
{[\mathrm{mm}]}\end{array}$} & \multicolumn{2}{|c|}{$[\mathrm{dB}]$} & \multicolumn{2}{c|}{$\begin{array}{c}\text { RMS } \\
{[\mu \mathrm{V}]}\end{array}$} \\
\cline { 3 - 6 } & & average & std dev. & average & std dev. \\
\hline 0.1 & 0.5 & 44.30 & 1.87 & 25.03 & 1.26 \\
\hline 0.2 & 0.5 & 44.61 & 3.37 & 22.83 & 1.16 \\
\hline 0.4 & 0.5 & 45.36 & 5.37 & 20.59 & 0.86 \\
\hline 0.1 & 0.75 & 42.44 & 1.68 & 31.25 & 1.05 \\
\hline 0.2 & 0.75 & 43.05 & 3.88 & 25.82 & 0.75 \\
\hline 0.4 & 0.75 & 47.21 & 7.74 & 22.22 & 0.88 \\
\hline 0.1 & 1 & 43.00 & 2.79 & 24.01 & 1.05 \\
\hline 0.2 & 1 & 43.71 & 3.93 & 21.91 & 0.95 \\
\hline 0.4 & 1 & 44.27 & 4.88 & 20.58 & 0.69 \\
\hline
\end{tabular}

Additionally the research results were presented graphically. Fig. 7 shows mean values of the AE signal amplitude as a function of cutting parameters while Fig. 8 shows the influence of cutting parameters on the AE signal RMS.

The analysis of data obtained in the research has shown that along with the increase in feed, the average value of the amplitude of the signal increases. The highest increase was observed at a cutting depth of $0.75 \mathrm{~mm}$ where the feed change from 0.1 to $0.4 \mathrm{~mm} / \mathrm{rev}$ caused an increase in the mean value of the amplitude of the signal by $11 \%$. However, the mean amplitude values of recorded signals were relatively small.

The opposite situation was noticed when the turning parameters influence the change in RMS. With the increase in feed, the average RMS value of the signal decreased. The biggest change was 
also observed at a depth of ap $=0.75 \mathrm{~mm}$. The reduction in RMS was at $29 \%$. Except of maximum RMS recorded for parameters ap $=0.75 \mathrm{~mm}$ and $\mathrm{f}=0.1 \mathrm{~mm} / \mathrm{rev}$ mean values of that parameters were similar and relatively low.

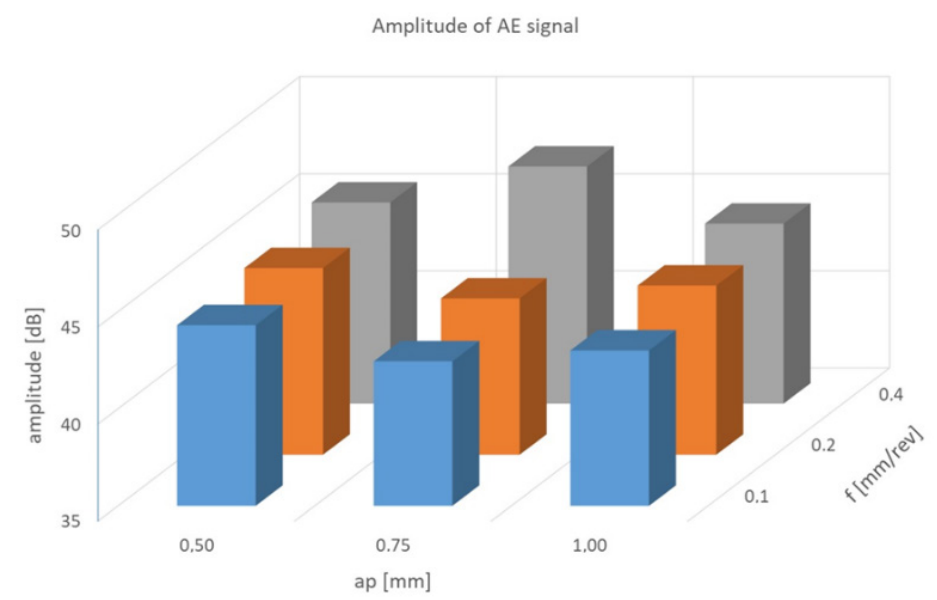

Fig. 7. The influence of cutting parameters on the AE signal amplitude

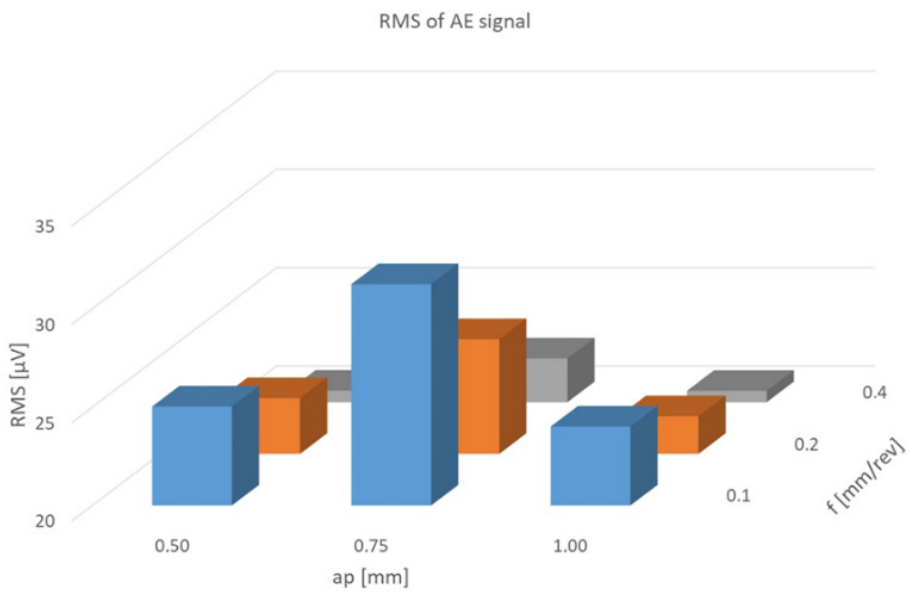

Fig. 8. The influence of cutting parameters on the AE signal RMS

\section{Summary}

Monitoring of turning allows to fast reacting the operator in case of changing parameters of the process. Ensuring correct cutting parameters during machining has a very large impact on the quality of the surface. There are many methods of monitoring turning process, e.g. temperature distribution - thermography methods, measurements of cutting forces, vibration, acoustic emission, etc.

In the research acoustic emission method was used. It allows observing the moment of occurrence of changes in the machining parameters that cause reducing of the process stability. There is a possibility of continuous controlling the process allowing informs the operator about additional circumstances affecting the quality of the turning process, e.g. damage of the cutting edge of the tool.

The application of acoustic emission method for monitoring turning process allowed establishing a stable lathing conditions based on AE signal parameters. With a range of parameters recorded during the test proved to be the most useful parameter was RMS of the signal. The lower the RMS value reached - the more stable lathing process was. A high RMS value may indicate the occurrence of rapid factors, e.g. chip breaking and wrapping, an increased level of vibration of the machine holder - tool - object system, etc. 
The analysis of data recorded in the research allowed to determine the turning parameters for which the process stability were on different levels. The test results indicate, that the higher instability of the process was during turning with parameters: ap $=0.75 \mathrm{~mm}$ and $\mathrm{f}=0.1 \mathrm{~mm} / \mathrm{rev}$.

The research results showed that the acoustic emission method could be used for monitoring the turning process. The study can also be the basis for determining optimal cutting parameters, for stability of the turning process.

\section{References}

[1] Baran, I., Identyfikacja uszkodzeń korozyjnych zbiorników na paliwa płynne metoda emisji akustycznej, Rozprawa doktorska, Krakow 2013.

[2] Baran, I., Nowak, M., Schmidt, J., Ono, K., Potentials of AE application in testing industrial pipelines, Advances in Acoustic Emission, USA 2007.

[3] Dudzik, K., The possibility of application acoustic emission method to optimize determination of finish lathing parameters, Journal of KONES Powertrain and Transport; Vol. 22, No. 4, Kudowa Zdrój 2015.

[4] Dudzik, K., The possibility of application acoustic emission method for controlling friction stir welding of $A W-5083$ aluminium alloy sheets, In METAL 2017: 26th International Conference on Metallurgy and Materials, pp. 1695-1700, Ostrava 2017.

[5] Dudzik, K., Ziegler, B., The possibility of application the acoustic emission method for monitoring flow of water within a ball valve, Journal of KONES Powertrain and Transport; Vol. 23, No. 4, pp. 87-92, Warszawa 2016.

[6] Gawlik, J., Krajewska-Śpiewak, J., Nowak, M., Emisja akustyczna jako wskaźnik początku dekohezji $w$ procesie frezowania, Innowacje w Zarządzaniu i Inżynierii Produkcji, T. 1, Oficyna Wydawnicza Polskiego Towarzystwa Zarządzania Produkcją, pp. 740-750, Krakow 2016.

[7] Labuda, W., The analysis of cutting tool geometric on cutting forces and surface roughness of steel applied to marine pumps shaft pins, Journal of KONES Powertrain and Transport, Vol. 21, No. 1, Jastrzębia Góra 2014.

[8] Labuda, W., The influence of cutting parameters on cutting forces and surface roughness, Journal of KONES Powertrain and Transport, Vol. 21, No. 3, Jastrzębia Góra 2014.

[9] Malecki I., Ranachowski J. (ed.), Emisja Akustyczna, źródta, metody, zastosowania, Pascal Publications, Warszawa 1994.

[10] Ziegler, B., Contribution of acoustic emission into optimal bearing lubrication, Journal of KONES, Warszawa 2007.

[11] Ziegler, B., Miszczak, A., Acoustic emission as a friction force indicator after test stands experiments, Journal of KONES, Warszawa 2007.

[12] Vallen Systemem, AMSY-6 Handbook, System description, Germany 2010. Manuscript received 15 March 2019; approved for printing 22 June 2019 